\title{
«Ода благодарности» А. П. Сумарокова: поэти- ческое новаторство в масонском тексте XVIII в.
}

\author{
Н. А. ГУСЬКОВ \\ Кафедра истории русской литературы, Санкт-Петербургский государственный университет, \\ Университетская наб., д. 11, RU-199034 Санкт-Петербург \\ E-mail: n.guskov@spbu.ru
}

(Received: 7 December 2015; accepted: 19 February 2016)

\begin{abstract}
The present paper analyzes the poem Ode to Gratitude by the famous Russian 18th-century poet A. P. Sumarokov, not yet studied by literary scholars. The analysis shows that Sumarokov, as the founder of Russian classicism, mixed elements of various genres and specific to different literary traditions in some of his poems, thus he can be called a forerunner to 19th-century lyrics. Sumarokov's stylistic innovations were facilitated by the necessity to encrypt Freemasonic ideas in a spiritual ode.

Keywords: Russian literature, 18th century, Sumarokov, Freemasons, ode, Russian lyrics
\end{abstract}

В последние десятилетия значительно возрос интерес литературоведов к творчеству А. П. Сумарокова. Многие исследователи не довольствуются уже общепринятыми, стройными, но не всегда подкрепленными конкретными доказательствами, концепциями своих предшественников и, подвергая их экспериментальной проверке материалом, обращаются непосредственно к текстуальному анализу. В результате наше представление о Сумарокове начало меняться. Все отчетливее обнаруживается оригинальность этого поэта, далеко не во всем подчинявшегося правилам нормативной поэтики, введению которой в России он сам сильно содействовал. Он не только отступает от отдельных жанровых канонов, но иногда смешивает в одном тексте элементы разных жанров, синтезирует различные, даже противостоящие друг другу традиции, оригинально трактует предмет, идею произведения, не всегда опираясь на соответствующее общее место, а исходя из индивидуального своего переживания. Творчество поэта отчасти уже предвосхищает в русской лирике то, что считают обычно открытием XIX столетия, сентиментальной и романтической эпохи.

Предлагаемая статья посвящена одному из наиболее впечатляющих в этом смысле произведений Сумарокова - «Оде благодарности» (СумАРОков 9: 215-218; далее этот текст цитируется в статье без специальных ссылок). Она, к сожалению, не привлекала серьезного внимания ученых и даже не переиздавалась в XX и XXI вв. Ода, вероятно, не до конца отделана автором: иногда не соблюдена мера стоп, за которой писатель в старости очень следил. Н. И. Новиков, публикуя оду в цитируемом собрании сочинений уже 
после смерти ее создателя, указал на утрату нескольких строф. Руководствовался ли он интуицией, знал полный вариант или намекал на цензурные изъятия - можно лишь догадываться. Далее мы будем, учитывая указание Новикова, все же рассматривать имеющийся текст как полный. Анализ позволяет предположить, что Новиков заблуждался, применив к новаторской риторической конструкции традиционные критерии. Возможно, ода отчасти сокращена и дополнена, компилирует созданные в разные годы фрагменты.

Даже при поверхностном прочтении видно, насколько по стилю и по трактовке проблем она отличается от современных ей стихов. При архаичности синтаксического и грамматического строя, она приближается к поэзии рубежа XVIII-XIX в., но и творческие принципы автора здесь обнаруживаются четко и демонстрируют, к какому литературному сдвигу приводит следование им на всех уровнях текста.

Новиков поместил «Оду благодарности» в раздел разных стихотворений, затрудняясь определить жанр точнее. В заглавии указано, что это ода, и по содержанию ее следовало причислить к духовным одам как рассуждение на философские темы, но строфы об «Ангеле Севера» показывают, что стихотворение написано на случай государственной жизни и содержит формулы торжественных од Сумарокова.

С «разными» одами стихотворение сближает применение одного из типов горацианской строфы (3 строки 6-стопного и четвертая - 3-стопного, а не 4-стопного ямба, как это чаще встречается, например, в «Гимне Солнцу» самого Сумарокова). Короткий последний стих делает резче pointe внутри каждого куплета и переход к следующей строфе. Анализ произведений Сумарокова показывает, что даже в высоких жанрах поэт нередко пользуется приемами салонного красноречия. Свойственные ему повороты темы и подмены мысли осуществляются в «Оде благодарности» особенно энергично, в значительной степени - именно за счет введения горацианской строфы. Ее интонации и ассоциативная закрепленность за определенными традициями приводят к тому, что в сумароковской оде совмещаются философская causerie (непринужденная беседа), пришедшая из просветительской литературы, благодушие и светлая меланхолия, расцветшие в более поздней сентиментальной поэзии, благородная ясность и взвешенное приятие жизни, восходящие к горацианству. Постоянная смена стилистических планов, сближение тона то с одой, то с иными жанрами, вероятно, и озадачивали современников, в том числе Новикова. Нам, в XXI в., ясно, что данная ода - синтетическое по жанровой природе сочинение, предвещающее лирику Львовского кружка, и даже XIX в.

Вопреки указанию Новикова на пропущенные строфы, ода по смыслу симметрично распадается на пять частей (по 4 куплета в каждой). Внутри них, за исключением центральной, построенной на восходящей градации, прослеживается общий, но не строго соблюдаемый композиционный принцип: в начале - одическое возвышение тона, затем - появление мрачных или смущающих образов, а в финале восстановление ощущения гармонии. 
Последние две фазы могут накладываться друг на друга. Каждая группа строф сближается с определенной литературной моделью, но содержит и противоположную эмоциональную тенденцию, развивающую то, что выражено в предыдущих частях, и подготавливающую следующие части. Разработка проблемы здесь соотносима с распределением действия по пяти актам классической драмы.

Начало оды отсылает к горацианской традиции. Западные источники стихотворения не установлены, но даже если они и существовали, переработка, вероятно, значительна. В I строфе поэт подчеркивает новаторский характер текста: «О, матерь честности и чистых душ утеха! / О благодарность, ты возвысь мой ныне глас! / Что редко делалось, я в том ищу успеха, / Пою тебя в сей час!». Ключевую здесь третью строку можно отнести как в целом к новаторскому творчеству Сумарокова, так и применительно к теме оды. Не только воспевание благодарности, но и трактовка ее поэтом синтетичны, соотнесены с объектами различного порядка, и это было ново. Так, немецкие авторы (Флеминг, Геллерт) в стихах на подобную тему благодарили лишь Бога, но не множество мирских людей, как это делает русский стихотворец.

С первой строфы осуществляется и стилевой синтез. С одной стороны, Сумароков настраивает на возвышенный лад, вводя риторические обращения, начинающиеся с «о», формулу «пою» (явные одические показатели) и прямо предлагая «возвысить глас». С другой - строфическая форма и подбор оборотов («матерь честности», «чистых душ утеха») отсылает к нравоучительному посланию, описательной и буколической поэзии. Возможно, именно в синтезе и видел поэт свое новаторство: «редко делалось» возвышение гласа при разговоре о благодарности - простом, естественном, но умилительном и почтенном нравственном качестве.

Светлое, возвышенное настроение меняется уже при переходе ко второй строфе, где сконцентрировано мрачное описание жизни, характерное для духовных од, элегий и сатир Сумарокова: «В живущем посреди обмана, лжи и лести / Душа без ясности и без величья ум: / Тупеет чувствие и, удаляясь чести, / Мутят теченье дум». Эта безысходная аллегорическая картина, состоящая из одушевленных абстракций, однако, двойственна. В ней при общей отрицательной тенденции заложена и характеристика идеала, поскольку сетует повествователь именно на то, что идеал поруган. Вторая строфа формирует представление о должном: душа обязана обладать ясностью, ум - величием, чувства - остротой, а человек в целом - следовать принципам чести.

Закономерно в III и IV строфах создается образ идеального персонажа, развеивающий мрачные мысли и приводящий читателя в конце первой части оды к душевной гармонии и сердечному умилению: «Кто истины всегда ни в чем не пременитель; / Кто памятует долг и в близости царей; / Коль счастлив смертный тот! Он истины хранитель, / Достоин алтарей! // Гнушается войти во вымыслы лукавы, / Удача льстивого его не ополчит; / Когда толпы людей во зло вперили нравы, / Он мыслит и молчит». Такой добродетельный 
муж напоминает горацианский идеал человека, соответственно ему трактованы истина и долг. Знаменательно, что служение им понимается как пассивный процесс: душевная твердость и невмешательство в недостойные дела. Именно такая позиция характерна для многих лириков рубежа XVIII и XIX вв. Интересен мотив молчания («он мыслит и молчит») как демонстрации верности истине, отказа от суеты - ложных слов и поступков. Речь идет не о безропотном приятии любого назначенного свыше удела (ср. «Оду, выбранную из Иова» Ломоносова), а о молчании, восходящем к античным философским учениям. Этот мотив, впервые в России введенный и разрабатывавшийся Сумароковым в разных жанрах, имел большое будущее в русской философской лирике (вспомним хотя бы «Не рассуждай, не хлопочи...» Ф. И. Тютчева).

Вторая часть оды отсылает к двум идеологическим изводам духовной поэзии Сумарокова: к восторженному приятию мира в его божественной гармонии (как в «Гимне Солнцу») и отчаянию перед вселенской суетой и неизбежностью гибели всего земного, прежде всего своей собственной (как в оде «На суету мира»). Стихотворец не имел четкой философской позиции, он далеко не всегда следовал церковной догме, интересовался теориями различных мыслителей, учением просветителей, масонством. Постоянным поискам и колебаниям способствовал и его характер, которому были свойственны аффектация и резкие переходы от восторженности к отчаянному унынию. Отражением сказанного и является «Ода благодарности». Мысленные взоры описанного в ней носителя горацианских добродетелей рождают противоположные настроения. Сначала звучат восхищение разумно и соразмерно устроенным миром и хвала его творцу: «И видит мыслию Правителя он света, / Благодеяние рачительна Отца, / Разумные дары во все дающа лета, / И щедрого Творца. // Едва глаза воззрят на цепь сию пространну, / На непрерывный сей величества закон, / Все славити велит нам милость несказанну, / Простерту без препон».

В том месте, где благостное приятие мира достигает предела, Новиков и усматривает пропуск строф. Действительно, далее следует эмоциональный срыв. Оказывается, в лучшем из возможных миров человек беспомощен и беззащитен, нуждается в постоянном покровительстве и руководстве. Эта мысль, осторожно введенная риторическим вопросом, подкрепленная тревожным словом «рок», постепенно возводится в гиперболу и радикально меняет настроение: «И до рожденья нам не надобны ль ограды? / Такой от существа нам рок определен: / Воспоможения потребны нам громады, / До гроба от пелен. // На шаре ломком толь, на сей нетвердой суше / Без благодетелей почти нельзя и жить: / Железные сердца, не могут люты души / Добру добром служить».

К концу второй части оды читатель вновь повергается в пучину отчаяния и сомнения. Опять меняется стиль, появляется устойчивый набор пессимистических эпитетов эпохи барокко, и создается пугающая картина: «на ломком шаре», «нетвердой суше» обитают «железные сердца» и «лютые 
души». Однако и здесь таится противоположное ощущение: жизненный путь упомянут инверсированно, в ретроспекции (от смерти к рождению, сначала гроб, потом колыбель), поэтому, вопреки обычному для Сумарокова образному ряду, мрачная аллегория заслонена светлой; утверждение о невозможности жизни в непрочном мире корректируется словом «почти» и существованием поддержки и благодарности. Центральное понятие оды разработано в третьей и четвертой ее частях.

Каждая строфа третьей части посвящена одному из объектов благодарности. Это нарастание выстроено диалектически: сначала речь идет о признательности за блага материальные, затем - за духовное общение. Наконец, воспета любовь, сочетание физического влечения с духовным. И последовательность куплетов, и характеристики «персонажей» демонстрируют приверженность Сумарокова просветительской нравоучительной поэзии. Очень ново то, что список лиц, к которым обязан человек испытывать благодарность, начинается с простонародья - крестьян и кормилицы: «Орет [пашет - Н. Г.] тот землю мне и плод на ней находит; / К покрытью тела тот одежды мне точет; / Иной мне храмины к жилищу мне возводит; / Всяк к ласке мя влечет. // Увидев только свет, себя млеком питаю: / Пекущейся злой рок младенцу отвратить, / Не одолженным ли я ей себя считаю / Добро добром платить?».

Поэт, по праву считающийся идеологом аристократии, - первый, кто воспел на Руси уважение к труду, признательность и даже «ласку» к кормильцу - к низшему сословию. Это не удивительно, если задуматься над дальнейшим путем нашей словесности; и все же поворот мысли неожиданный для современников и для нас: Сумароков, начавший ту традицию, которая привела к творчеству «кающихся дворян», склонности к подобному покаянию сам еще не проявлял.

Повествователь не говорит о матери, дающей жизнь (в контексте сумароковской картины мира дискуссионен вопрос, достойно ли это благодарности), но заботливо упоминает кормилицу. В XVIII и даже XIX в., когда дворянки редко сами кормили младенцев грудью (изменяться ситуация начала с распространением руссоизма) и уделяли им меньше ласки, нежели няньки, мы часто встречаем бо́льшую нежность и признательность к кормилице, чем к родительнице. Красноречивое свидетельство - биография А. С. Пушкина, воспевшего и обессмертившего Арину Родионовну. Отношения Сумарокова с матерью были напряженными, она не разделяла взглядов и вкусов сына, поддерживала всех враждовавших с ним родственников. О привязанности поэта к кормилице не известно, но знаменательно, что именно в строфе о ней благодарность впервые в оде декларируется не как естественное доброе влечение (см. предыдущий куплет), а как священный долг. При помощи скрепа строфа о кормилице полемически отсылает к финалу второй части: в жестоком мире, где «не могут люты души добру добром служить», именно мысль о той, что вспоила беспомощное дитя своим молоком, рождает представление о нравственном долге «добро добром платить». Это побуждение трактуется как естественное в духе моральных теорий просветителей. 
Существенно и презрение сословных различий: автор, исходя из социальной практики эпохи, вряд ли мыслил кормилицу представительницей своего круга.

Градация в третьей части выстроена лишь отчасти по социальному принципу: сословная принадлежность каждого нового персонажа все менее очевидна, зато параллельно возрастает степень сердечной привязанности повествователя к этим лицам. Поскольку автор - представитель благородного сословия (он не пашет и не ткет), возникает ощущение, что по мере приближения к повествователю повышается социальный статус персонажей. Это, впрочем, не очевидно. Если общественное положение пахаря, ткача и строителя фиксировано, нельзя сказать того же о кормилице, тем более, наставнике, друге, супруге (вспомним и разночинное происхождение большинства преподавателей на Руси в старину, и относительное свободомыслие Сумарокова, и его женитьбу на крестьянке). Четкое указание на социальность проблемы и одновременное перенесение ее в этический и психологический план - характерная черта сентиментального уклона просветительской словесности.

Показательно для сознания XVIII в. воспевание благодарности наставнику и другу в одной строфе: «Приставником учусь, а другом утешаюсь, / Кто здравы мне свои советы подает; / Учениями я и дружбой украшаюсь / И счастья вижу свет».

Не случайно второй стих можно отнести синтаксически к обоим лицам, упомянутым в первой строке, а глаголы «учусь» и «утешаюсь» образуют параллелизм. Поэт предстает как человек эпохи Просвещения: не только благословляет роль учителя и его влияние на жизнь, но и специфически трактует дружбу. Оценив уже ее исключительное значение для личности, он еще не переживает это чувство в духе возвышенной аффектации, свойственной сентименталистам. И дружба, и учение воспринимаются как синтез приятного и полезного, а наставник и друг, в идеале, воплощаются в одном лице. Прообразом подобного друга-советчика явился Ментор, воспитатель Телемака. На таком понимании взаимодействия воспитания и дружбы строятся важнейшие педагогические системы XVIII в. (не исключая Руссо). Литература той эпохи не раз воссоздавала тип, подобный герою аббата Прево, резонеру Тибержу, который беззаветно предан беспутному кавалеру де Грие, но неустанно и утомительно поучает дорогого ему человека. Такова же часто и функция наперсника в классической трагедии, причем в эпоху Просвещения она явно актуализируется. Наперсники сумароковских тиранов, наперсницы героинь, в основном, занимаются наставлением. Впрочем, переосмысление понятия дружбы в сентиментальную, романтическую эпоху не истребило тип «друга-учителя». Не с этой ли традицией связан Андрей Штольц, герой И. А. Гончарова?

Градацию в третьей части завершает прославление любви: «Но счастие мое еще прострется боле, / Как брачную свечу любовию зажгу: / И что подобно сей небесной смертным доле, / Коль быть любим могу?». Не останавливаясь на характеристике этого чувства, отметим «естественный» для каждой 
из жанровых форм, синтезированных в оде, несколько абстрактный, а оттого - возвышенно идеалистический оттенок упоминания о любви в противовес той земной чувственности, которая отличает эклоги, песни и элегии Сумарокова. Не случайно указание на брачную свечу: любовь, освященная божественным законом, могла упоминаться и в оде; напротив, в предисловии к эклогам подчеркнуто, что изображаются чувства пастухов «златого века», когда не существовало института брака. «Ода благодарности» - один из немногих примеров описания любви в творчестве Сумарокова в духе сентиментальной нравоучительной поэзии.

Вообще, центральная часть текста отсылает к идеям «естественной морали», теории о заложенных в человеческой природе побуждениях к добру, трактует понятие благодарности отчасти в духе принципов «разумного эгоизма» (для взаимной поддержки люди должны воздавать добром тем, кто помогает им реализовывать и защищать их «естественные права»). Упомянутые в оде типы соотносятся с амплуа так называемой сентиментальной драмы, «слезной комедии», пропагандирующей учение просветителей. И влекущие господина к ласке слуги, и почтенные кормилицы, и друзья-воспитатели, и счастливые добродетельные супруги наводнили сцену во второй половине XVIII в. Сумароков дал своим «персонажам» характеристики, какие они приобрели в том жанре, о котором он с такой ненавистью писал Вольтеру. Вероятно, ода написана еще до распространения «слезной комедии»: мы наблюдаем параллельную реализацию родственных тенденций, которые, воплотившись в сумароковском творчестве и «слезной» драме, вступили в конфликт.

Интересные параллели к третьей части оды прослеживаются в творчестве Д. И. Фонвизина. Ограничимся постановкой проблемы. Значимый для оды контекст - и «Послание к слугам», и «Бригадир», и «Недоросль», и некоторые прозаические сочинения. Понятие благодарности неоднократно осмыслялось Фонвизиным, в частности, в обеих его комедиях. Способность к этому чувству сделана одним из критериев оценки личности: крайности такой подход достигает в намеренном подчеркивании соответствующих черт поведения Митрофанушки и противостоящих ему резонеров, например, Софьи. Подобно Сумарокову, Фонвизин изображая формы благодарности и неблагодарности, уделял внимание как социальному, так и нравственному, и психологическому аспектам проблемы. Интересно, отношение Митрофана к г-же Простаковой и Еремеевне. Безусловно, героя позорит неблагодарное отношение не только к матери, но и к мамке (не случайно подчеркнуто, что Еремеевна не просто нянчится с недорослем, но и вскормила его). Фразе г-жи Простаковой: «Пусть же все добрые люди увидят, что мама [кормилица Н. Г.] и что мать родная» (Фонвизин 1: 128), - присущи как прямое значение, изобличающее некоторые особенности психологии героини, так и иронический подтекст, опровергающий позицию Простаковой и позволяющий иначе взглянуть на расстановку действующих лиц. Впрочем, в силу законов жанра или особенностей темперамента и мировоззрения Фонвизина, проблема 
благодарности (за исключением, конечно, отношений резонеров к Стародуму) подается иронически. Так, в «Послании к слугам» кучер, лакей и даже старый камердинер, муж няньки повествователя, к которым выражена и симпатия, и признательность, поданы насмешливо. Сентиментальная, но серьезная постановка проблемы Сумароковым в какой-то степени оказывается доступнее читателю не екатерининской, а нашей эпохи.

Точно датировать «Оду благодарности» невозможно. Между тем датировка прояснила бы, не пародировал ли Фонвизин в «Послании к слугам» начало четвертой части: «А ты наставник мой, отец и мой учитель, / Который основал и сердце мне и мысль, / Почтенный ментор! ты души моей рачитель; / Трудом признанья числь!», ср. фонвизинское обращение к Шумилову: «Любезный дядька мой, наставник и учитель, / И денег, и белья, и дел моих рачитель!» (Фонвизин 1: 209). Одним из любимых развлечений молодого Фонвизина, как он сам вспоминал впоследствии, было передразнивать Сумарокова (Фонвизин 2: 99). Если основной текст оды написан в 1760-х гг., когда писатели враждовали, и был известен в рукописи, то вольнодумно настроенный молодой сочинитель мог не без удовольствия осмеять приведенные строки. «Послание к слугам» основано на пародийном снижении высоких понятий и оборотов речи или на их оксюморонном сближении с низкими, бытовыми. В данном случае, при одной из интерпретаций сумароковского источника, пародия приобретает кощунственный смысл, вполне гармонирующий с общей идеей текста Фонвизина. Что же могло непосредственно вызвать выпад Фонвизина, если гипотеза верна? Смысл IV части оды содержит подтекст. Нарастание, организующее предыдущие строфы, достигло в этом фрагменте кульминации, между тем смысл его не вполне ясен. В тексте уже создалась двойная логика, позволяющая двояко истолковывать это место.

Исходя из законов традиционной духовной поэзии, перед нами - обращение к Отцу небесному, ведь родитель земной, обрекая свое дитя на жизненные испытания и скорби, в системе пессимистических настроений поэта заслуживал меньшей признательности, чем иные лица. Между тем стиль четвертой части оды неожиданно нейтрален, далек от парения. Недопустимое применение к Создателю имени «ментор», в те времена лишь наполовину нарицательного, показывает, что без раздумья отнесет эти строки к Богу лишь поверхностный читатель.

Череда «персонажей» III части, логика их последовательности позволяют понять данный куплет как обращение к отцу кровному, земному. Однако и это прочтение плохо согласуется со стилистическим оформлением темы. Функции родителя, помимо упоминания слова «отец», трактуются здесь исключительно в духовном плане: наставник, учитель, ментор, основатель мысли и сердца (явно разумеется не плоть, а метонимически - чувство). Вслед за строфой о любви, где мы отметили синтез земного и небесного, можно и здесь видеть продолжение такого же синтеза, но это поверхностный план произведения, рассчитанный на непосвященного читателя. На самом деле происходит подмена темы, следовательно - и подмена идеи всей оды. 
Повествователь обращается не к небесному, а к земному отцу, но не к кровному, а к духовному, причем это не христианский священник, которого человек XVIII в. вряд ли осмелился бы назвать ментором. «Ода благодарности» - один из ранних образцов русской масонской поэзии. Такая интерпретация объясняет и слог, органичный для мистической сентиментальной лирики той эпохи: рассуждение на моральные темы, сдержанное, но чувствительное, несколько отвлеченное, но доступное по языку широкой публике, популяризировало и исподволь внедряло идеи масонства. У большинства сторонников этого учения в XVIII в. не вызывали резкого отторжения многие положения просветительства и иных философских систем. Масонская идейная основа «Оды благодарности» объясняет, почему так органично объединились в ней элементы разных литературных моделей и не слишком согласующиеся умонастроения. Понятна и ирония Фонвизина, который в период «Послания к слугам» был враждебен масонам.

Строфы, обращенные к «отцу» (духовному наставнику), подтверждают масонский характер подтекста: «Коль должности во мне любовь уже явленна, / Коль подлости бегу, гнушаяся ея, / И человечеством днесь грудь одушевленна, / Чиста ль душа моя? // Худых примеров я противлюся стремленью, / И в самый смертный час я буду при себе; / Мя совесть угрызать не будет к озлобленью, / И так всем должен я тебе. // Пусть небо кончит век и истребит мя прежде, / Аx! нежели бы я твои труды когда забыл, / В какой бы мог воззреть на Солнце я надежде, / Себе б противен был». Чувствительный читатель прочтет эти строки как выражение сыновней любви и семейного долга, религиозный - почувствует, как в смятенной душе побеждает благочестивое стремление исполнить долг христианина пред Творцом. Посвященный читатель легко узнает знакомые мотивы масонской литературы, которая и строится на многослойном смыслопорождении - для непосвященных и для избранных.

Идея самоусовершенствования, проявляющегося не в отрешенности от мирской жизни, а в служении человечеству во имя любви к нему, строгая личная ответственность за поступки, необходимость преодоления порочных склонностей нечистой от рождения души, исполнение долга и перед Создателем, и перед Наставником, необходимость платить труды трудами - все это основы масонского учения, поданные без чрезмерной тенденциозности, но от того не менее узнаваемые. Посвященный читатель и предшествующие мотивы оды ретроспективно воспримет теперь в масонском ключе, и тогда иной смысл приобретут и обличительная картина жестокости нравов, и образ добродетельного мужа, и молчание, и уважительное внимание к труженикам, к кормилице, и синтез дружбы и наставления, и одухотворение любви, и сама идея благодарности не только к Творцу, но и к творению, к окружающим людям. Масон Новиков это понимал, потому его указание на пропуск строф при видимой связности и симметрии текста все же заслуживает внимания. Он мог знать и адресата, и обстоятельства создания текста, и его первый вариант. Нам масонская деятельность Сумарокова известна мало, но 
не стоит приуменьшать влияние масонства на мировоззрение и творчество поэта. Он написал даже песенку, оправдывающую сторонников тайного мистического общества: «Кто хулит франкмасонов / За тайный их устав, / Что те не чтут законов / Своих держатся прав: // Когда бы ты спросился, / Как верен франкмасон [то есть во что верит - Н. Г.], / В котором он родился, / Тот держит и закон [не изменяет той религии, к которой принадлежит от рождения. Далее речь идет о высокой честности и человеколюбии масонов - Н. Г.]. [...] / Словом, тебе сказати, / Он честный человек, / А тайну их спознати / Нельзя тебе вовек» (СумАРоков 1935: 158). Песенная форма позволяет предположить: Сумароков рассчитывал на то, что этот текст широко распространится и рассеет предрассудки.

Новиков указал на пропуск строф перед последней частью оды. Она введена посредством неожиданного поворота темы. Возможно, однако, последние 4 строфы добавлены позже: «О Ангел Севера, прехвален ты колико! / Твоя Аврора нам прекрасный день сулит: / Неблагодарность тмит; достоинство толико / Тебя любить велит. // В восторге чтя того, с усердием мы таем, / Который нам тебя в сии пути вовлек, / Мы милости твои дни обще почитаем, / Того преклонный век. // От радости своей он слезы проливает, / Зря плод своих трудов, который им созрел, / Душа его в твоем объятьи пребывает, / Он все в тебе обрел. // О если бы и все, как ты, благоволили / И восхищали дух к творящим благо им / И в добродетели всегда благотворили / С бесстрастием своим».

«Ангелом Севера» именуется, видимо, великий князь Павел Петрович, Аврора (рассвет) чьей жизни предвещала подданным прекрасный день. На вероятность гипотезы указывает сходный фрагмент из речи Сумарокова на день рождения великого князя 1761 г.: «Предходящая Солнцу на небеса Аврора, никогда нам пришествие Солнца ложно не предвозвещала: младенчество такое, каковое Ты, Государь Великий Князь, имеешь, нас обмануть не может. Везде о Тебе носится молва, что Тобою исполнится надежда наша: исполнится; все те, которые Тобою разговаривать удостоилися, то свидетели [...] О час! дражайший час! час вожделенный! источник нового нашего благополучия, в который сие сокровище даровалося России, в который сей Ангел нисшел на землю!» (СумАРоков 2: 239-240). С Ангелом, впрочем, в одах Сумароков сравнивал и Екатерину II. Однако масонская проблематика стихотворения позволяет предполагать, что посвящено оно Павлу Петровичу. Повседневный круг общения наследника составляли масоны (Г. Н. Теплов, И. Г. и З. Г. Чернышевы, Н. И. и П. И. Панины). Формируя будущего монарха, они стремились ему привить свои религиозные и нравственные принципы, чему не препятствовал и законоучитель Платон (Левшин), по совету которого Сумароков переложил целиком «Псалтирь». Сближение Павла Петровича с масонами увенчалось их триумфом позднее, но процесс общения шел постоянно и не мог не быть известен писателю. Не Н. И. Панин ли разумеется под тем, кто вовлек Ангела Севера «в сии пути»? Отношения Сумарокова с этим вельможей были доброжелательными. В ответе на прошение 
поэта от 15 апреля 1770 года, выдержанное в фамильярных тонах, Панин, зачеркнув официальную формулу, внесенную секретарем, послал стихотворцу дружеский привет (Письма 1980: 141, 213). Видеть в человеке «преклонного века» архиепископа Платона нет оснований, в момент смерти Сумарокова тому было 40 лет. Панин и Сумароков - ровесники, и эпитет «преклонный» уместен с поправками на критерии XVIII в.

Интересно, что наставники наследника престола, помимо прочих добродетелей, обращали особенное внимание на воспитание в нем чувства благодарности, причем как раз в том же духе, в каком описано оно в оде Сумарокова. Об этом, например, свидетельствуют записки С. А. Порошина: «После стола просил его высочество графа Ивана Григорьича и потом его превосходительство Никиту Ивановича [Чернышева и Панина - Н. Г.] весьма умильно и прилежно, чтоб для сына кормилицы его, которому пять лет, сделать какое-нибудь счастье: определить его во флот или в иное какое место. Его превосходительство Никита Иванович обещал доложить ее величеству, чтоб указано было того мальчика определить в морской кадетский корпус, хотя он и не дворянин, однако во уважение того, что мать его была кормилица его высочества. Мы все весьма радовались, приметя такие в государе великом князе чувства благодарности» (Порошин 1844: 57-58).

Последние 4 куплета, быть может, написаны и вставлены к какому-то случаю. Активизация масонов вокруг великого князя началась в 1769 году. В это же время ухудшаются отношения поэта с властью. В период вхождения Павла Петровича в совершенные лета (1771-1772 гг.) и позднее Сумароков проявляет интерес и явную симпатию и к наследнику, и к его окружению, что послужило для Г. А. Гуковского одним из аргументов для причисления писателя к аристократической оппозиции Екатерине II. Не исключено, что финал оды отражает эти настроения, здесь возлагается высокая нравственная ответственность на царственного адресата. Основная же часть оды, сама по себе вполне законченная, появилась, видимо, раньше, до публикации в 1769 году «Послания к слугам», до поступления Фонвизина на службу к Панину и до начала активной борьбы Сумарокова со «слезной комедией».

Финал оды являет в Сумарокове изысканного салонного поэта XVIII века, путем эффектных риторических приемов построившего речь так, что философское нравоучение, сохраняя самостоятельную ценность, превратилось в развернутое вступление к восхвалению наследника престола; придворный комплимент обрекал адресата на высокую моральную ответственность; сквозь изложение общих мест духовной и поучительной лирики проступала их трактовка неортодоксальным и тайным учением; обращение к отвлеченным проблемам подключало исповедальные фрагменты и намекало на духовную общность повествователя и высокого адресата. Стилевое многообразие, ориентация на различные ассоциативные поля, придали произведению гибкость, динамизм. Как способный ученик лукавого Вольтера Сумароков избегает прямолинейности суждений: каждое при желании можно перетолковать иначе. В результате, текст приобретал неодинаковый смысл для разных 
читателей. Учитывалась не только степень посвященности в тайные доктрины, но и придворная позиция. При необходимости обращение к «Ангелу Севера» можно было трактовать и как восхваление императрицы, у которой был почтенный и доверенный наставник преклонных лет - И. И. Бецкой. Это маскировочное прочтение, но подобный прием характерен для старинной придворной словесности и не принижает ни значения, ни достоинств «Оды благодарности».

Итак, внимательное прочтение текста позволяет нам увидеть стилевое новаторство, жанровую неоднозначность и смысловую многослойность забытого лирического произведения Сумарокова, в котором он отчасти предвосхищает поэзию последующих поколений. Стихотворец синтезирует в пределах духовной оды элементы, восходящие к различным жанрово-стилевым традициям. Это оказывается возможным благодаря тому, что религиозноэтическую тему автор разрабатывает средствами салонного красноречия и трактует ее одновременно в нескольких планах: ортодоксальном, просветительском и масонском. Быть может, детальный анализ и других стихотворений Сумарокова принесет новые наблюдения, уточняющие, наш взгляд, на старинную русскую поэзию.

\section{Литература}

Письма 1980 = Письма русских писателей ХVIII века. Ленинград, 1980.

Порошин 1844 = Порошин С. А. Записки, служащие к истории его императорского высочества благоверного государя џесаревича и великого князя Павла Петровича, наследника престолу российского. Санкт-Петербург, 1844.

СумАРОКОВ = СумАРОКОВ А. П. Полное собрание всех сочинений в стихах и в прозе в 10 частях. Москва, 1787.

СумАРОКОВ 1935 = СумАРОКов А. П. Стихотворения. Ленинград, 1935.

Фонвизин = Фонвизин Д. И. Собрание сочинений в 2 томах. Москва-Ленинград, 1959. 